\title{
Effects of dopant anions and $N$-substituents on the electrochemical behavior of polypyrrole films in propylene carbonate solution
}

\author{
Hochun Lee, Haesik Yang, Juhyoun Kwak * \\ Department of Chemistry, Korea Advanced Institute of Science and Technology (KAIST), 373-1 Kusong-dong Yusong-gu, \\ 373-1 Kusong-dong yusong-gu, Taejon 305-701, Republic of Korea
}

Received 5 November 2001; received in revised form 29 November 2001; accepted 29 November 2001

\begin{abstract}
The electrochemical properties of poly( $N$-ethylpyrrole) (PEPy) and poly( $N$-methylpyrrole) (PMPy) films in propylene carbonate (PC) solution, where ion transport is anion-specific, has been investigated using the cyclic electrochemical quartz crystal microbalance (EQCM) technique and electrochemical impedance techniques. The type of dopant anion $\left(\mathrm{PF}_{6}^{-}\right.$vs. $\left.\mathrm{ClO}_{4}^{-}\right)$used for the film preparation and the $N$-substituents (ethyl vs. methyl) have profound effects on the solvent transport behavior, charge capacity, and ionic resistance of the films. (c) 2002 Elsevier Science B.V. All rights reserved.
\end{abstract}

Keywords: Poly( $N$-ethylpyrrole); Poly( $N$-methylpyrrole); EQCM; EIS; Anion transport; Solvent transport

\section{Introduction}

There have been significant efforts to customize or tailor-make the properties of conducting polymers for a desired application such as sensors, energy storage devices, and corrosion inhibitors [1]. The key step in the progress of these applications is to understand the mechanism of mass transport during the redox reaction, which governs the electrochemical properties of conducting polymers. Extensive work has been performed on mass transport in conducting polymers [2,3]. However, it is still far from full understanding because mass transport is rather complex; ion transport is not permselective, solvent transport accompanies ion transport, and ion/solvent transports are both time and potential dependant.

The characteristics of conducting polymers strongly depend on their polymerization condition such as the film growth rate, the nature of solvent, and the kind and concentration of dopant anion [4-7]. Another possible way to give variation to polymer properties is to modify the chemical structure of monomer. Diaz et al. [8] pre-

\footnotetext{
${ }^{*}$ Corresponding author. Tel.: +82-42-869-2833; fax: +82-42-8692810.

E-mail address: jhkwak@kaist.ac.kr (J. Kwak).
}

pared the series of poly $(\mathrm{N}$-alkyl pyrrole $)$ and showed that the nature of substituent affects the various properties such as the redox potential, degree of oxidation, density, and conductivity.

In general, it has been known that ion transport is anion specific in the cases of poly( $N$-substituted pyrrole) films in both aqueous and aprotic solutions [9-11]. To our knowledge, however, no systematic study has been reported yet on the effect of $N$-substituents of polypyrrole films on their mass transport behavior.

In the present study, mass transport behavior of $\operatorname{poly}(N$-ethylpyrrole) (PEPy) and poly $(N$-methylpyrrole) (PMPy) films in propylene carbonate (PC) solutions was investigated with the cyclic electrochemical quartz crystal microbalance (the cyclic EQCM) technique $[12,13]$ and the electrochemical impedance spectroscopy (EIS) [14-16]. Two kinds of dopant anion, $\mathrm{PF}_{6}^{-}$and $\mathrm{ClO}_{4}^{-}$were used in preparing PEPy and PMPy films. First, the solvent transport behavior and the charge capacity of each film were compared using the cyclic EQCM technique both in $\mathrm{PF}_{6}^{-}$-containing and $\mathrm{ClO}_{4}^{-}$containing solutions. Second, to examine the dependence of the mass transport kinetics on dopant anion and $N$-substituent, ionic resistance $\left(R_{\mathrm{D}}\right)$ was measured using EIS. Finally, the effects of dopant anion and $N$ substituent on the electrochemical properties of films 
were discussed in terms of their morphological difference.

\section{Experimental}

All the chemicals used in this study are of reagent grade and electrolytes were dried at $80{ }^{\circ} \mathrm{C}$ under vacuum before use. A standard three-electrode cell was used for all electrochemical measurement with an $\mathrm{Ag} \mid \mathrm{Ag}^{+}(0.01$ $\mathrm{M} \mathrm{AgNO}_{3}$ in $\mathrm{PC}$ ) reference electrode and a $\mathrm{Pt}$ wire counter electrode. All potentials are quoted against the saturated calomel electrode (SCE). A $6 \mathrm{MHz}$ AT-cut quartz crystal (Inficon, NY) coated with $\mathrm{Au}, 0.32 \mathrm{~cm}^{2}$ in area, served as the working electrode. The experimental setup for the EQCM, the electrochemical impedance, and the electromechanical impedance measurements was the same as that reported previously [17]. All the films were polymerized galvanostatically at $0.2 \mathrm{~mA} \mathrm{~cm}^{-2}$ in PC solutions containing $0.1 \mathrm{M}$ monomer and $0.1 \mathrm{M}$ $\mathrm{TEAPF}_{6}$ or $\mathrm{TEAClO}_{4}$. For convenience, the films grown in $\mathrm{TEAPF}_{6}$ solutions are represented as $\mathrm{PEPy} / \mathrm{PF}_{6}$ or $\mathrm{PMPy} / \mathrm{PF}_{6}$, whereas the films grown in $\mathrm{TEAClO}_{4}$ solutions are shown as $\mathrm{PEPy} / \mathrm{ClO}_{4}$ or $\mathrm{PMPy} / \mathrm{ClO}_{4}$. The charge consumed during the polymerization was $300 \mathrm{mC} \mathrm{cm}^{-2}$ for all the films. After polymerization, the films were washed with pure solvent and transferred into an Ar-filled glove box. The cyclic EQCM and the electrochemical impedance experiments were performed in the glove box, and the electromechanical impedance experiment was performed in the atmosphere in a close cell. All the cyclic EQCM data was measured during the second cycle of two consecutive cycles after being held at the positive potential limit unless otherwise noticed. Scan rate was $5 \mathrm{mV} \mathrm{s}^{-1}$ for all the cases. In our previous report [17], we showed that the linear relationship between the mass change and the resonant frequency of an oscillating quartz crystal can be proved by comparing the mass change obtained from the resonant frequency with that obtained from the electromechanical impedance. In every case reported in this study, there was no significant difference between the two mass changes. Consequently, mass change can be obtained from resonant frequency change without consideration of the morphological changes of polymer films. The electromechanical impedance data and the electrochemical impedance data were fitted by using the complex nonlinear least-squares (CNLS) fitting program. The CNLS program used in this work is the LEVM program (Scribner, VA).

\section{Results and discussion}

\subsection{Mass transport behavior of PEPy films}

There are two methods to correlate the electric response and gravimetric response. The first one is to compare current $(I)$ and mass change rate $(G=\mathrm{d} M / \mathrm{d} t)$. To be compared with $I, G$ is normalized according to Eq. (1)

$G_{\mathrm{n}}=-\left(z F / W^{\prime}\right) G$,

where $z$ is the charge of an ion, $F$ is the Faraday constant and $W^{\prime}$ is the apparent molar mass of charge compensating species. If the normalized mass change rate $\left(G_{\mathrm{n}}\right)$ is larger than $I$ at any potential, it means that the $W^{\prime}$ value used in Eq. (1) is smaller than the actual value. This method is very useful to monitor potentialdependent mass transport as shown in our previous reports $[10,17-19]$. The second one is to compare charge change $(\Delta Q)$ and mass change $(\Delta M)$, in which the average apparent molar mass of charge compensating species $\left(W_{\text {avg }}^{\prime}\right)$ is obtained by Eq. (2)

$W_{\text {avg }}^{\prime}=-z F(\Delta M / \Delta Q)$.

Both methods were employed in the following section for the cyclic EQCM experiments.

Fig. 1 shows the cyclic voltammograms and $G_{\mathrm{n}}$ diagrams for PEPy films. In each $G_{\mathrm{n}}$ diagram, the molar mass of $\mathrm{PF}_{6}^{-}\left(W_{\mathrm{PF}_{6}^{-}}\right)$or the molar mass of $\mathrm{ClO}_{4}^{-}\left(W_{\mathrm{ClO}_{4}^{-}}\right)$is regarded as $W^{\prime}$. During the redox reaction of a $\mathrm{PEPy} / \mathrm{PF}_{6}$ film in $\mathrm{LiPF}_{6}$ (Fig. 1(a)), $G_{\mathrm{n}}$ is larger than $I$ over the whole potential range. Because the actual $W^{\prime}$ is not uniform over the whole potential range, $W_{\text {avg }}^{\prime}$ value was obtained. In all experiments, $W_{\text {avg }}^{\prime}$ value at the anodic scan is similar to that at the cathodic scan within an experimental error. Thus, $W_{\text {avg }}^{\prime}$ at the only cathodic scan was represented in Table 1. For Fig. 1(a), $W_{\text {avg }}^{\prime}$ is 215, which is much larger than $W_{\mathrm{PF}_{6}^{-}}(=145)$. This indicates that neutral electrolyte or solvent moves in the same direction as $\mathrm{PF}_{6}^{-}$movement. However, $W_{\text {avg }}^{\prime}$ is 222 for a $\mathrm{PEPy} / \mathrm{PF}_{6}$ film in $\mathrm{TEAPF}_{6}$ (Table 1 ), which is very similar to that in $\mathrm{LiPF}_{6}$. If there were neutral salt transport, $W_{\text {avg }}^{\prime}$ value in $\mathrm{TEAPF}_{6}$ would be much larger than that in $\mathrm{LiPF}_{6}$ due to the larger molar mass of TEAPF $_{6}$. Therefore, it shows that neutral electrolyte transport is negligible and solvent transport is more probable. Assuming that only anion transport and solvent transport take place, $W^{\prime}$ can be expressed as below.

$W^{\prime}=W_{-}+Y W_{s}$,

where $W_{-}$and $W_{\mathrm{s}}$ are the molar masses of an anion and a solvent, respectively, and $Y$ is the number of accompanying solvent molecules per anion. As shown in Table 1, the average $Y\left(Y_{\text {avg }}\right)$ values for $\mathrm{PEPy} / \mathrm{PF}_{6}$ films in $\mathrm{LiPF}_{6} /$ $\mathrm{PC}$ and $\mathrm{TEAPF}_{6} / \mathrm{PC}$ are 0.7 and 0.8 , respectively. This means that some PC molecules move in the same direction as $\mathrm{PF}_{6}^{-}$transport.

On the contrary, during the redox reaction of a $\mathrm{PEPy} / \mathrm{ClO}_{4}$ film in $\mathrm{LiClO}_{4}$ (Fig. 1(b)), $G_{\mathrm{n}}$ is slightly smaller than $I$ over the whole potential range. $W_{\text {avg }}^{\prime}$ value is 81 , which is smaller than $\mathrm{W}_{\mathrm{ClO}_{4}^{-}}(=99.5)$. This means that cation, neutral salt, or solvent transport may occur 


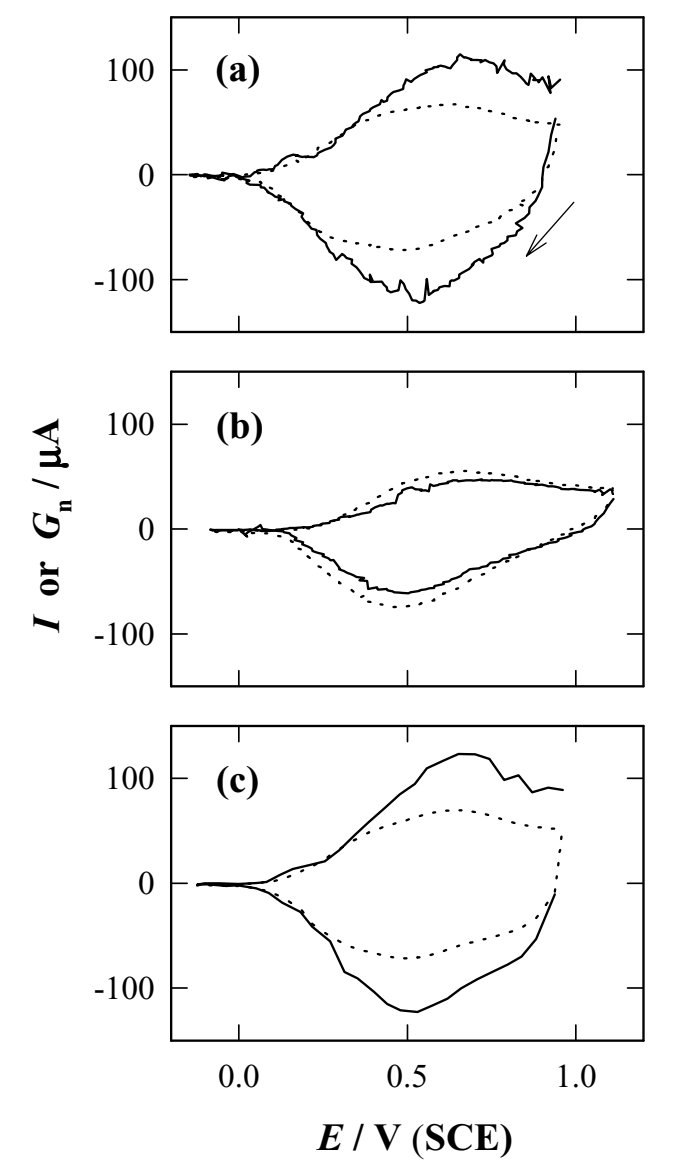

Fig. 1. Cyclic voltammograms $(I$ vs. $E ; \cdots)$ ) and normalized mass change rate diagrams $\left(G_{\mathrm{n}}\right.$ vs. $E$; $\longrightarrow$ ) for (a) $\mathrm{PEPy} / \mathrm{PF}_{6}$ in $1 \mathrm{M}$ $\mathrm{LiPF}_{6}\left(W^{\prime}=W_{\mathrm{PF}_{6}^{-}}\right)$, (b) $\mathrm{PEPy} / \mathrm{ClO}_{4}$ in $1 \mathrm{M} \mathrm{LiClO}_{4}\left(W^{\prime}=W_{\mathrm{ClO}_{4}^{-}}\right)$, and (c) $\mathrm{PEPy} / \mathrm{PF}_{6}$ in $1 \mathrm{M} \mathrm{LiClO}_{4} / \mathrm{PC}\left(W^{\prime}=W_{\mathrm{ClO}_{4}^{-}}\right)$.

in the opposite direction to $\mathrm{ClO}_{4}^{-}$movement. However, $W_{\text {avg }}^{\prime}$ value for a $\mathrm{PEPy} / \mathrm{ClO}_{4}$ film in $\mathrm{TEAClO}_{4}$ is 83 , which is not very different from 81 . This excludes the possibility of the transport of cation/neutral salt. Thus, smaller $W_{\text {avg }}^{\prime}$ value is due to the solvent transport occurring in the opposite direction to anion transport. The $Y_{\text {avg }}$ values for PEPy $/ \mathrm{ClO}_{4}$ films are -0.2 , which means that some PC molecules move in the opposite direction to $\mathrm{ClO}_{4}^{-}$transport. It is interesting to note that the direction of solvent transport in Fig. 1(a) is opposite to that in Fig. 1(b). In addition, the charge capacity for
Fig. 1(a) is larger than Fig. 1(b). $\Delta Q$ values during the cathodic scan are 8.4 and $7.0 \mathrm{mC}$, respectively (Table 1). These differences may be due to the difference in the anion used either at film growth or the cyclic EQCM experiments. To make this point clear, the cyclic EQCM experiment for a $\mathrm{PEPy} / \mathrm{PF}_{6}$ film in $\mathrm{LiClO}_{4} / \mathrm{PC}$ (Fig. 1(c)) was performed. The data was obtained after the several redox cycles to make sure the complete anion exchange. The cyclic voltammogram in Fig. 1(c) looks very similar to that in Fig. 1(a) rather than Fig. 1(b). The $\Delta Q$ value is $8.5 \mathrm{mC}$, which is nearly the same as that in Fig. 1(a). $G_{\mathrm{n}}$ is larger than $I$ around peak potentials in Fig. 1(c), which is the behavior observed in Fig. 1(a). These observations support the idea that the nature of anion incorporated during a film preparation governs the charge capacity and solvent transport behavior of PEPy films. Conclusively, $\mathrm{PEPy} / \mathrm{PF}_{6}$ films show larger charge capacities than $\mathrm{PEPy} / \mathrm{ClO}_{4}$ films, and solvent transport occurs in the same direction to anion transport for $\mathrm{PEPy} / \mathrm{PF}_{6}$ films whereas it occurs in the opposite direction to anion transport for $\mathrm{PEPy} / \mathrm{ClO}_{4}$ films.

\subsection{Mass transport behavior of PMPy films}

Fig. 2 shows the cyclic EQCM results of PMPy films. In each $G_{\mathrm{n}}$ diagram, $W_{\mathrm{PF}_{6}^{-}}$or $W_{\mathrm{ClO}_{4}^{-}}$is regarded as $W^{\prime}$. For a $\mathrm{PMPy} / \mathrm{PF}_{6}$ film in $\mathrm{LiPF}_{6}$ (Fig. 2(a)), $G_{\mathrm{n}}$ is slightly smaller than $I$ over the whole potential range. As shown in Table $2, W_{\mathrm{avg}}^{\prime}$ is 124 , which is smaller than $W_{\mathrm{PF}_{6}^{-}}$. Similar $W_{\mathrm{avg}}^{\prime}$ is obtained in $\mathrm{TEAPF}_{6}(=116)$, which implies that the smaller $W_{\text {avg }}^{\prime}$ is due to solvent in the opposite direction to anion transport.

For a PMPy $/ \mathrm{ClO}_{4}$ film (Fig. 2(b)), the cyclic voltammogram shows reduced peak currents and the cathodic peak is broadened and shifted to more negative value as compared with that in Fig. 2(a). The counter flux of solvent also occurs in a $\mathrm{PMPy} / \mathrm{ClO}_{6}$ film in $\mathrm{LiClO}_{4}$ (Fig. 2(b)) and a PMPy/PF 6 film in $\mathrm{LiClO}_{4}$ (Fig. 2(c)). Thus, solvent transport occurs to the opposite direction to anion transport in all the three cases of PMPy films, which is in contrast with the results of PEPy films. $\Delta Q$ values of Figs. 2(a)-(c) are 5.8, 5.2, and $5.8 \mathrm{mC}$, respectively. Note that these values and the differences between them are smaller than those of PEPy films.

Table 1

$W^{\prime}$ and $Y$ values obtained from the cyclic EQCM experiments for poly( $N$-ethylpyrrole) films (Fig. 1)

\begin{tabular}{llccc}
\hline Film & Electrolyte & $W_{\text {avg }}^{\prime \text { a }}$ & $Y_{\text {avg }}$ b & $\Delta Q$ \\
\hline $\mathrm{PEPy} / \mathrm{PF}_{6}$ & $\mathrm{LiPF}_{6}$ & 215 & 0.7 & 8.4 \\
$\mathrm{PEPy} / \mathrm{PF}_{6}$ & $\mathrm{TEAPF}_{6}$ & 222 & 0.8 & 7.0 \\
$\mathrm{PEPy} / \mathrm{ClO}_{4}$ & $\mathrm{LiClO}_{4}$ & 81 & -0.2 & \\
$\mathrm{PEPy} / \mathrm{ClO}_{4}$ & $\mathrm{TEAClO}_{4}$ & 83 & -0.2 & 8.5 \\
$\mathrm{PEPy} / \mathrm{PF}_{6}$ & $\mathrm{LiClO}_{4}$ & 154 & 0.5 & \\
\hline
\end{tabular}

${ }^{\mathrm{a}} W_{\mathrm{avg}}^{\prime}=F(\Delta \mathrm{M} / \Delta Q)$ during the cathodic scan $\left(\mathrm{g} \mathrm{mol}^{-1}\right)$.

${ }^{\mathrm{b}} Y_{\mathrm{avg}}^{\mathrm{avg}}=\left(W_{\mathrm{avg}}^{\prime}-W_{-}\right) / W_{\mathrm{PC}}, W_{\mathrm{PF}_{6}^{-}}=145, W_{\mathrm{ClO}_{4}^{-}}=99.5$, and $W_{\mathrm{PC}}=102$. 


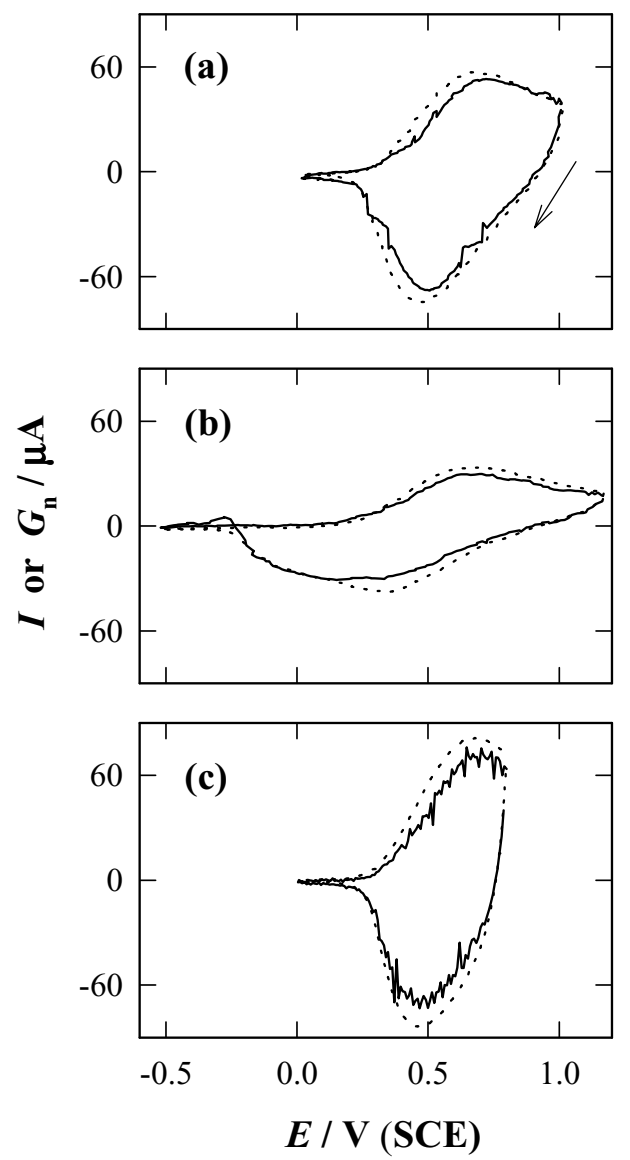

Fig. 2. Cyclic voltammograms $(I$ vs. $E ; \cdots)$ and normalized mass change rate diagrams $\left(G_{\mathrm{n}}\right.$ vs. $E ;-$ ) for (a) $\mathrm{PMPy} / \mathrm{PF}_{6}$ in $1 \mathrm{M} \mathrm{LiPF}_{6}$ $\left(W^{\prime}=W_{\mathrm{PF}_{6}^{-}}\right)$, (b) $\mathrm{PMPy} / \mathrm{ClO}_{4}$ in $1 \mathrm{M} \mathrm{LiClO}_{4}\left(W^{\prime}=\mathrm{W}_{\mathrm{ClO}_{4}^{-}}\right)$, and (c) $\mathrm{PMPy} / \mathrm{PF}_{6}$ in $1 \mathrm{M} \mathrm{LiClO}_{4}\left(W^{\prime}=W_{\mathrm{ClO}_{4}^{-}}\right)$.

\subsection{Ionic resistance of PEPy and PMPy films}

Fig. 3 shows electrochemical impedance plots for the cases studied in Fig. 1 (Fig. 3(a)) and Fig. 2 (Fig. 3(b)). Electrochemical impedance plots are composed of two parts. One is the finite diffusion region at low frequency and the other is the semi-infinite diffusion region at high frequency $[15,20]$. Except for a $\mathrm{PMPy} / \mathrm{ClO}_{4}$ film in $\mathrm{LiClO}_{4}$, both regions are observed within the measured frequency range. Ionic resistance $\left(R_{\mathrm{D}}\right)$ values shown in Table 3 are obtained by fitting electrochemical imped- ance data with the modified Randle's equivalent circuit $[15,20]$. As shown in Table $3, R_{\mathrm{D}}$ increases in the following series:

$R_{\mathrm{D}}\left(\mathrm{PF}_{6}, \mathrm{ClO}_{4}\right)<R_{\mathrm{D}}\left(\mathrm{PF}_{6}, \mathrm{PF}_{6}\right)<R_{\mathrm{D}}\left(\mathrm{ClO}_{4}, \mathrm{ClO}_{4}\right)$

where $R_{\mathrm{D}}\left(\mathrm{PF}_{6}, \mathrm{ClO}_{4}\right)$, for example, represents $R_{\mathrm{D}}$ of $\mathrm{ClO}_{4}^{-}$for a $\mathrm{PEPy} / \mathrm{PF}_{6}$ (or a $\mathrm{PMPy} / \mathrm{PF}_{6}$ ) film. Note that $\mathrm{PEPy} / \mathrm{PF}_{6}$ (or $\mathrm{PMPy} / \mathrm{PF}_{6}$ ) films show smaller $R_{\mathrm{D}}$ than $\mathrm{PEPy} / \mathrm{ClO}_{4}$ (or $\mathrm{PMPy} / \mathrm{ClO}_{4}$ ) films. This indicates that $R_{\mathrm{D}}$ is affected by the nature of anion used in the film growth. In addition, PEPy films show smaller $R_{\mathrm{D}}$ than PMPy films, which shows that the $R_{\mathrm{D}}$ also depends on the kind of $N$-substituent of pyrrole monomer. Moreover, $R_{\mathrm{D}}$ of $\mathrm{ClO}_{4}^{-}$is smaller than that of $\mathrm{PF}_{6}^{-}$in a $\mathrm{PEPy} / \mathrm{PF}_{6}$ (or a $\mathrm{PMPy} / \mathrm{PF}_{6}$ ) film. This can be ascribed to the smaller ionic size of $\mathrm{ClO}_{4}^{-}$than that of $\mathrm{PF}_{6}^{-}$. Although the difference of their crystallographic ionic radius is not so large [21], its effect on $R_{\mathrm{D}}$ can be much significant within the film because the environment in the interior film is very different from that in the electrolyte solution.

\subsection{Dependence of film morphology on dopant anion and $N$-substituent}

From the experimental results, we showed the electrochemical properties such as charge capacities, the solvent transport behavior, and the ionic resistance depend on the kind of anion used at the film growth and $N$-substituent of pyrrole. These dependencies can be explained by introducing the term of "ion channel". If ion channel size is large enough, solvent transport may take place in the same direction as anion transport. In addition, less hindered ion transport within a film will result in larger ionic conductivity and the enhanced kinetics will increase the charge capacity of the films. On the other hand, if ion channel size is small, solvent transport will occur in the opposite direction to anion transport to offer the space for incoming anion or to refill the anion vacancy. Moreover, ionic conductivity and charge capacity will decrease due to the large steric hindrance on ion transport. Indeed, similar concept can be found in other studies on other conducting polymers $[19,22,23]$. On the basis of this hypothesis, it can be

Table 2

$W^{\prime}$ and $Y$ values obtained from the cyclic EQCM experiments for poly( $N$-methylpyrrole) films (Fig. 2)

\begin{tabular}{llccc}
\hline Film & Electrolyte & $W_{\text {avg }}^{\prime a}$ & $Y_{\text {avg }} \mathrm{b}^{\mathrm{a}}$ & $\Delta Q$ \\
\hline $\mathrm{PMPy} / \mathrm{PF}_{6}$ & $\mathrm{LiPF}_{6}$ & 124 & -0.2 & 5.8 \\
$\mathrm{PMPy} / \mathrm{PF}_{6}$ & $\mathrm{TEAPF}_{6}$ & 116 & -0.3 & 5.2 \\
$\mathrm{PMPy} / \mathrm{ClO}_{4}$ & $\mathrm{LiClO}_{4}$ & 82 & -0.2 & \\
$\mathrm{PMPy} / \mathrm{ClO}_{4}$ & $\mathrm{TEAClO}_{4}$ & 77 & -0.2 & 5.8 \\
$\mathrm{PMPy} / \mathrm{PF}_{6}$ & $\mathrm{LiClO}_{4}$ & 81 & -0.2 & \\
\hline
\end{tabular}

${ }^{\mathrm{a}} W_{\text {avg }}^{\prime}=F(\Delta M / \Delta Q)$ during the cathodic scan $\left(\mathrm{g} \mathrm{mol}^{-1}\right)$.

${ }^{\mathrm{b}} Y_{\text {avg }}=\left(W_{\text {avg }}^{\prime}-W_{-}\right) / W_{\mathrm{PC}}, W_{\mathrm{PF}_{6}^{-}}=145, W_{\mathrm{ClO}_{4}^{-}}=99.5$, and $W_{\mathrm{PC}}=102$. 


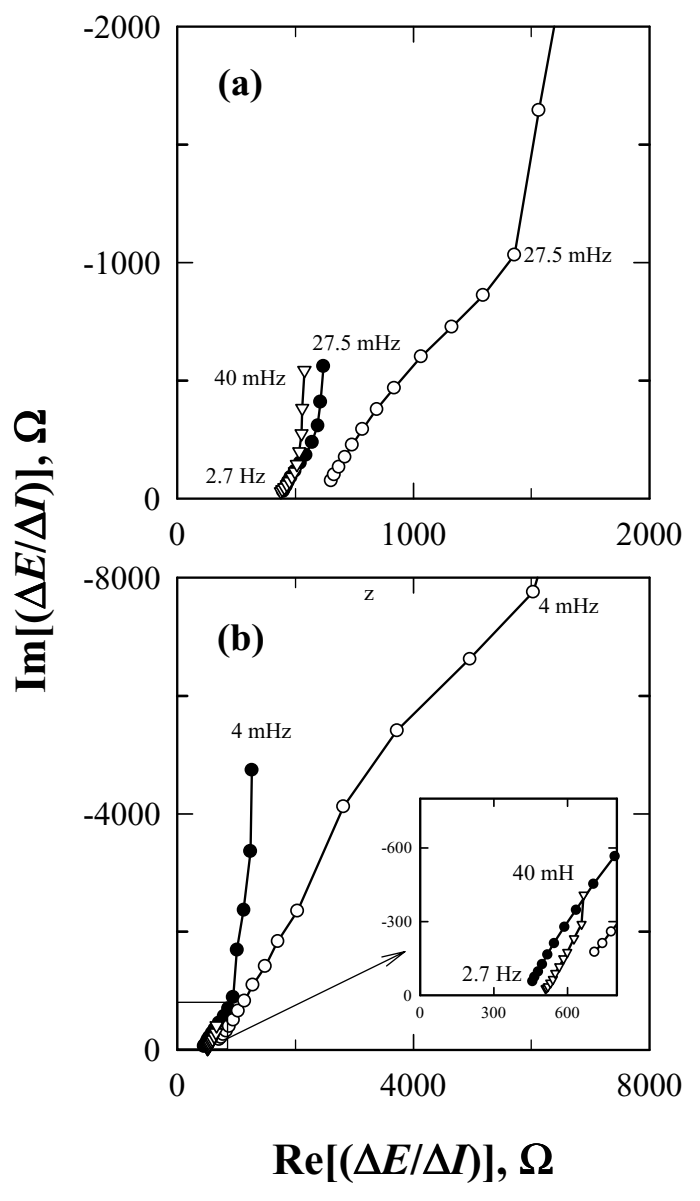

Fig. 3. Electrochemical impedance $(\Delta E / \Delta I)$ plots for (a) PEPy films $\left(\mathrm{PEPy} / \mathrm{PF}_{6}\right.$ in $\mathrm{LiPF}_{6}(\bullet), \mathrm{PEPy} / \mathrm{ClO}_{4}$ in $\mathrm{LiClO}_{4}(\circ), \mathrm{PEPy} / \mathrm{PF}_{6}$ in $\mathrm{LiClO}_{4}(\nabla)$, and (b) PMPy films $\left(\mathrm{PMPy} / \mathrm{PF}_{6}\right.$ in $\mathrm{LiPF}_{6}(\bullet), \mathrm{PMPy} / \mathrm{ClO}_{4}$ in $\mathrm{LiClO}_{4}(\circ), \mathrm{PMPy} / \mathrm{PF}_{6}$ in $\mathrm{LiClO}_{4}(\nabla)$.

Table 3

Ionic resistance $\left(R_{\mathrm{D}}\right)$ obtained in the electrochemical impedance experiments (Fig. 3)

\begin{tabular}{llr}
\hline Film & Electrolyte & \multicolumn{1}{c}{$R_{\mathrm{D}}{ }^{\mathrm{a}}$} \\
\hline $\mathrm{PMPy} / \mathrm{PF}_{6}$ & $\mathrm{LiPF}_{6}$ & 2440 \\
$\mathrm{PMPy} / \mathrm{ClO}_{4}$ & $\mathrm{LiClO}_{4}$ & $>20000$ \\
$\mathrm{PMPy} / \mathrm{PF}_{6}$ & $\mathrm{LiClO}_{4}$ & 690 \\
$\mathrm{PEPy} / \mathrm{PF}_{6}$ & $\mathrm{LiPF}_{6}$ & 650 \\
$\mathrm{PEPy} / \mathrm{ClO}_{4}$ & $\mathrm{LiClO}_{4}$ & 3780 \\
$\mathrm{PEPy} / \mathrm{PF}_{6}$ & $\mathrm{LiClO}_{4}$ & 410 \\
\hline
\end{tabular}

${ }^{\mathrm{a}}$ Obtained at $-0.6 \mathrm{~V}$ for PEPy films and $-0.4 \mathrm{~V}$ for PMPy films $(\Omega)$.

proposed that a $\mathrm{PEPy} / \mathrm{PF}_{6}$ (or a $\mathrm{PMPy} / \mathrm{PF}_{6}$ ) film has a larger ion channel than a $\mathrm{PEPy} / \mathrm{ClO}_{4}$ (or $\left.\mathrm{PMPy} / \mathrm{ClO}_{4}\right)$ film. However, solvent transport in PMPy films always occurs to the opposite direction to anion transport irrespective of the dopant anion used at the film growth. In addition, a PMPy film shows smaller charge capacity and larger $R_{\mathrm{D}}$ than a PEPy film. Thus, it seems that PMPy films have smaller ion channel than PEPy films. The apparent difference between PMPy and PEPy is their $N$-substituents, methyl vs. ethyl group. In our previous reports on poly ( $N$-phenylpyrrole) (PPhPy) [16], solvent transport behavior was very similar to that of PEPy rather than PMPy, but the amount of solvent transport $\left(Y_{\text {avg }}\right)$ in PPhPy is somewhat smaller than that in PEPy. These results imply that the channel size of PPhPy is smaller than that of PEPy but larger than that of PMPy. Thus, the size of $N$-substituent does not seem to be the only factor to determine the ion channel size. Indeed, Diaz et al. [8,24] explained the influence of phenyl substituent in terms of dipole moment of pyrrole monomer and emphasized the importance of the electronic effect of the unsaturated substituents. Conclusively, the kind of dopant anion and the steric and electronic natures of $N$-substituent are important factors to determine the morphology of poly $(N$-substituted pyrrole) films and their electrochemical properties.

\section{Conclusions}

Electrochemical properties of PEPy films such as solvent transport behavior, charge capacity, and the ionic resistance depend on the kind of dopant anion used at the film growth. In case of PMPy films, solvent transport behavior is not affected by the kind of dopant anion. Moreover, PEPy films show larger charge capacity and ionic conductivity than PMPy films. These differences are suggested to be due to the their morphology difference determined at the stage of film growth.

\section{Acknowledgements}

This work was supported by the Korea Science and Engineering Foundation through the MICRO center at KAIST and partially supported by the Brain Korea 21 Project in 2001.

\section{References}

[1] W.-K. Lu, S. Basak, R.L. Elsenbaumer, in: T.A. Skotheim, R.L. ElsenbaumerJ.R. Reynolds (Eds.), Handbook of Conducting Polymers, Marcel Dekker, New York, 1998, p. 881.

[2] G. Inzelt, in: A.J. Bard (Ed.), Electroanalytical Chemistry, vol. 18, Marcel Dekker, New York, 1994, p. 89.

[3] M.E.G. Lyons, in: M.E.G. Lyons (Ed.), Electroactive Polymer Electrochemistry Part 1, Plenum, New York, 1994, p. 1.

[4] T. Osaka, K. Naoi, H. Sakai, S. Ogano, J. Electrochem. Soc. 134 (1987) 285.

[5] J.M. Ko, H.W. Rhee, S.-M. Park, C.Y. Kim, J. Electrochem. Soc. 137 (1990) 905.

[6] K. Kanamura, Y. Kawai, S. Yonezawa, Z. Takehara, J. Phys. Chem. 98 (1994) 2174.

[7] D.J. Walton, S. Ryley, I.V.F. Viney, E. Taylor, Adv. Mater. Opt. Electron. 6 (1996) 395. 
[8] A.F. Diaz, J.I. Castillo, K.K. Kanazawa, J.A. Logan, M. Salmon, O. Fajardo, J. Electroanal. Chem. 133 (1982) 233.

[9] B. Massoumi, A. Entezami, Eur. Polym. J. 37 (2001) 1015.

[10] H. Yang, J. Kwak, J. Phys. Chem. B 101 (1997) 4656.

[11] G. Schiavon, G. Zotti, N. Comisso, A. Berlin, G. Pagani, J. Phys. Chem. 102 (1992) 1982.

[12] D.A. Buttry, M.D. Ward, Chem. Rev. 92 (1992) 1355.

[13] D.A. Buttry, in: A.J. Bard (Ed.), Electroanalytical Chemistry, vol. 17, Dekker, New York, 1991, p. 1.

[14] P.G. Bruce, in: J.R. MacCallumC.A. Vincent (Eds.), Polymer Electrolyte Reviews-1, Elsevier, London, 1987 (Chapter 8).

[15] W.J. Albery, C.M. Elliott, A.R. Mount, J. Electroanal. Chem. 288 (1990) 15.
[16] C. Deslouis, M.M. Musiani, B. Tribollet, M.A. Vorotyntsev, J. Electrochem. Soc. 142 (1995) 1902.

[17] H. Yang, J. Kwak, J. Phys. Chem. B 101 (1997) 774.

[18] H. Yang, J. Kwak, J. Phys. Chem. B 102 (1998) 1982.

[19] H. Lee, H. Yang, J. Kwak, J. Phys. Chem. B 103 (1999) 6030.

[20] G.L. Duffit, P.G. Pickup, J. Chem. Soc., Faraday Trans. 88 (1992) 1417.

[21] N. Ue, J. Electrochem. Soc. 141 (1994) 3336.

[22] M. Kalaji, L. Nyholm, L.M. Peter, J. Electroanal. Chem. 313 (1991) 271.

[23] J. Ouyang, Y. Li, J. Appl. Polym. Sci. 59 (1996) 1827.

[24] A.F. Diaz, A. Martinez, K.K. Kanazawa, M. Salmon, J. Electroanal. Chem. 130 (1981) 181. 